\title{
LEDGINs, a novel class of antivirals targeting HIV integrase during integration and assembly
}

\author{
Zeger Debyser \\ From Frontiers of Retrovirology: Complex retroviruses, retroelements and their hosts \\ Cambridge, UK. 16-18 September 2013
}

Integrase strand transfer inhibitors (INSTIs) such as raltegravir have become a key component of antiviral therapy. We have recently described the development of a novel class of integration inhibitors, 2-(quinolin-3-yl) acetic acid derivatives, that potently block HIV replication (Christ et al. Nature Chemical Biology 2010). Unlike clinically approved INSTIs, these compounds do not bind to the catalytic site of HIV integrase (IN). As allosteric inhibitors they bind to the LEDGF/ p75 binding pocket in integrase, hence the class name LEDGINs. This prevents the interaction with LEDGF/p75, a molecular tether of HIV IN, and inhibits the catalytic activities of IN. Detailed mechanism of action studies reveal that the allosteric mode of inhibition is due to the stabilization of the IN dimer. Recently, we demonstrated that LEDGINs also inhibit late stage HIV replication by stabilization of IN multimers. Evidence suggests that LEDGF/ p75 may play a role in this process. Lack of cross-resistance with available IN inhibitors and potency due to the multistep inhibition, support the further clinical development of LEDGINs.

Submit your next manuscript to BioMed Central and take full advantage of:

- Convenient online submission

- Thorough peer review

- No space constraints or color figure charges

- Immediate publication on acceptance

- Inclusion in PubMed, CAS, Scopus and Google Scholar

- Research which is freely available for redistribution

\section{Biomed Central}

(c) 2013 Debyser; licensee BioMed Central Ltd. This is an Open Access article distributed under the terms of the Creative Commons Attribution License (http://creativecommons.org/licenses/by/2.0), which permits unrestricted use, distribution, and reproduction in any medium, provided the original work is properly cited. 